\title{
Quantification of Upper Limb Motor Function in Acquired Brain Injuries
}

\section{Catano $\mathrm{A}^{1 *}$ and Manto $\mathbf{M}^{2}$}

${ }^{1}$ University Hospital Center of Charleroi, Rehabilitation Hospital, Rue de Gozée 706, 6110 Montigny-le-Tilleul, Belgium

${ }^{2}$ FNRS-ULB Érasme, Route de Lennik 808, 1070 Bruxelles, Belgium

\section{Editorial}

The upper limb is crucial for daily life activities. In particular, the thumb plays a decisive role in manipulating objects. The column of the thumb is formed by the first metacarpal bone (M1) and two knuckles $(\mathrm{P} 1, \mathrm{P} 2)$ and the interphalangeal joint allows the movement of the distal portion, including flexion and extension movements.

Pathologies of the upper limb commonly impair daily life activities and movements of the hand are frequently altered in brain-damaged patients. For instance, a stroke in the sylvian territory will severely affect the movements of the contralateral hand. Fractures, arthrosis, "trigger finger" and ulnar collateral ligament thumb injury often cause difficulties in buttoning a shirt, pulling a zipper, tying shoelaces, cutting food, opening a bottle or a package, making a grip to hold a container, writing a text message on a smartphone, turning a key in a lock, opening a door, ...
Despite the major importance of the upper limb in manual activities and the high frequency of involvement of the hand in brain-damaged patients, clinicians still lack a simple test to assess the performance of repetitive motor task implying the thumb. Kinematic analyzes can be performed, but they remain complex and they cannot be easily applied at the patient's bedside.

Therefore, we aim to develop a non-invasive test to study the motor function of the upper limb in brain-damaged adult patients treated in our Department of Neurorehabilitation.

Results obtained in the affected member will be compared with those of the unaffected side and to normative values obtained in healthy subjects.

We will assess laterality with the Edinburgh Handedness Inventory and functional capacity of the hand with the Cochin Hand Function Scale.
*Corresponding author: Catano A, Neurologist and Neurophysiologist, Head of Department of Neurorehabilitation, University Hospital Center of Charleroi, Rehabilitation Hospital, Rue de Gozée 706, 6110 Montigny-le-Tilleul, Belgium, Tel: +32 71923 742; Fax +32 71922 951; E-mail: antonio.catano@chu-charleroi.be

Received September 01, 2015; Accepted September 02, 2015; Published September 08, 2015

Citation: Catano A, Manto M (2015) Quantification of Upper Limb Motor Function in Acquired Brain Injuries. Int J Neurorehabilitation 2: e110. doi:10.4172/2376$0281.1000 \mathrm{e} 110$

Copyright: $\odot 2015$ Catano A, et al. This is an open-access article distributed under the terms of the Creative Commons Attribution License, which permits unrestricted use, distribution, and reproduction in any medium, provided the original author and source are credited. 